\title{
Mortality of discards from southeastern Australian beach seines and gillnets
}

\author{
Matt K. Broadhurst ${ }^{1, *}$, Russell B. Millar ${ }^{2}$, Craig P. Brand ${ }^{1}$, Sebastian S. Uhlmann ${ }^{3}$ \\ ${ }^{1}$ New South Wales (NSW) Department of Primary Industries, Fisheries Conservation Technology Unit, PO Box J321, \\ Coffs Harbour, New South Wales 2450, Australia \\ ${ }^{2}$ Department of Statistics, The University of Auckland, Private Bag 92019, Auckland, New Zealand \\ ${ }^{3}$ School of Environmental Sciences and Natural Resources Management, University of New England, PO Box J321, \\ Coffs Harbour, New South Wales 2450, Australia
}

\begin{abstract}
Two experiments were done in an Australian estuary to quantify the mortalities and contributing factors for key species discarded during 8 and 9 deployments of commercial beach (or shore) seines and gillnets, respectively. In both experiments, bycatches (2347 individuals comprising 16 species) were handled according to conventional practices and assessed for immediate mortalities before live samples of selected species were discarded into replicate cages along with appropriate controls, and monitored for short-term mortalities $(\leq 10 \mathrm{~d})$. All of the seined or gilled fish were alive prior to discarding. During the beach seine experiment, $20 \%$ of caged seined-and-discarded surf bream Acanthopagrus australis $(\mathrm{n}=290)$ were dead after $5 \mathrm{~d}$, with most mortalities occurring between the second and fifth day. In the gillnet experiment, 42 and $11 \%$ of gilled-and-discarded A. australis $(\mathrm{n}=161)$ and lesser salmon catfish Neoarius graeffei $(\mathrm{n}=67)$, respectively, died during a $10 \mathrm{~d}$ monitoring period, mostly within the first $5 \mathrm{~d}$. There were no deaths in any controls for these fish. Mixed-effects logistic models revealed that the mortality of A. australis discarded from both gears was significantly $(\mathrm{p}<0.01)$ and negatively correlated with their total length, while $N$. graeffei had a significantly $(\mathrm{p}<0.05)$ greater $(5$-fold) probability of dying when jellyfish Catostylus sp. were present in the gillnet. Simple modifications to the operations of beach seines and gillnets and/or post-capture handling procedures, such as close regulation of size selectivity for the target species, careful removal of fish from meshes, and abstention from setting during high abundances of jellyfish will maximise the survival of discarded bycatch.
\end{abstract}

KEY WORDS: Beach seine $\cdot$ Bycatch $\cdot$ Discards $\cdot$ Gillnet $\cdot$ Mortality $\cdot$ Unaccounted fishing mortality Resale or republication not permitted without written consent of the publisher

\section{INTRODUCTION}

A total of 830 commercial fishers are legally endorsed to use a range of active and passive gears to target various teleosts, crustaceans and cephalopods throughout 76 estuaries in New South Wales (NSW), Australia, and land almost $5000 \mathrm{t}$ of catch valued at AU\$ 21 million per annum (NSW Department of Primary Industries, www.dpi.gov.au). Up to $65 \%$ of the total catch (worth AU\$ 9.5 million) is harvested with beach (or shore) seines and gillnets deployed by 139 and 487 fishers in 40 and 35 estuaries, respectively.
Catches can comprise more than 70 species, but predominantly consist of fewer than 10 mugilids, sparids, sillaginids, gerreids, girellids or platycephalids (Gray et al. 2001, 2005a).

In addition to the harvested catches, estuarine beach seiners and gillnetters also discard large quantities of bycatch, including individuals of the targeted species smaller than minimum legal (MLTL) or commercial total lengths (MCTL) (Gray 2002, Gray et al. 2001, 2004, 2005a, Gray \& Kennelly 2003). For example, during a 12 mo observer-based study of beach seiners in 3 estuaries, Gray et al. (2001) and Gray \& Kennelly 
(2003) estimated that between 85 and $269 \mathrm{t}$ of bycatch (38 and $59 \%$ of the total catches) were discarded at each location. Comparable 10 and 3 mo studies with gillnetters in 6 and 3 estuaries, respectively, showed that while the average volumes of bycatch were considerably less than those observed for beach seines, extrapolated annual estimates were up to $65 \mathrm{t}$ for some estuaries (Gray 2002, Gray et al. 2004). Further, the bycatches of both gears included large numbers of juveniles of commercially and recreationally important species, and especially surf bream Acanthopagrus australis (<250 mm TL).

Concerns over the potential for wide scale, unaccounted fishing mortalities of key discards precipitated attempts at improving the selectivity of beach seines and gillnets. Most of this work involved gear-based technical modifications, such as alternative rigging configurations and materials for gillnets (Gray et al. 2005b), strategic escape panels for beach seines (Gray et al. 2000) and increases in the sizes of mesh for both gears (Kennelly \& Gray 2000, Broadhurst et al. 2003, 2006a, 2007a).

Differences among the behaviour, size and morphology of the various species and their temporal and spatial distribution among catches preclude the development of a single modification to eliminate all bycatches for each gear type. Nevertheless, some simple changes significantly improved selectivity for a range of species, and those changes have either been legislated, or are currently being considered. In particular, Broadhurst et al. (2006a, 2007a) showed that the smallest mesh size used in the bunts and codends of beach seines could be almost doubled from 30 to $57 \mathrm{~mm}$, with negligible changes in catches of most of the key targets. Similarly, based on clear negative relationships between mesh size and the catches of undersize Acanthopagrus australis and luderick Girella tricuspidata ( $<250 \mathrm{~mm}$ TL) in gillnets, the minimum mesh size was recently increased from 80 to $95 \mathrm{~mm}$ for configurations deployed for more than $3 \mathrm{~h}$ (Gray et al. 2005a). Gillnets with $80 \mathrm{~mm}$ mesh are still permitted under NSW state law if the nets are set and immediately retrieved, partially because these gears are used to target flathead mullet Mugil cephalus (which at a MLTL of $300 \mathrm{~mm}$ have a narrower girth than other key species; Broadhurst et al. 2006a), but also because of the perception that short deployments result in few discard mortalities (Gray et al. 2005a).

While technical modifications to most configurations of beach seines and gillnets should address many of the concerns associated with bycatch, because of the large diversity in species assemblages and abundances at least some unwanted organisms will still be caught and discarded. Few data are available on the fate of these organisms (but see Kennelly \& Gray
2000), or the factors contributing towards any mortalities. Such information is required to provide a more comprehensive assessment of the impacts of both of these fisheries in estuaries and, equally importantly, to develop technical solutions that maximise survival and/or validate existing practices (such as short deployments of gillnets).

Reviews of the relevant literature indicate that there is considerable variability in the mortality of bycatch discarded from commercial fishing gears, which can be attributed to a range of biotic and abiotic factors (Davis 2002, Broadhurst et al. 2006b). Key parameters identified for gillnets include the mesh configuration (Vander Haegen et al. 2004, Bettoli \& Scholten 2006), deployment duration (Murphy et al. 1995, Farrell et al. 2000, Bettoli \& Scholten 2006), water temperature (Murphy et al. 1995, Bettoli \& Scholten 2006), depth (Basaran \& Samsun 2004) and the species (Manire et al. 2001) and fish size (Gallinat et al. 1997). Much less information is available for beach seines (but see Fritz \& Johnson 1987), although some of the above factors, as well as those identified for towed gears (such as catch volume; Broadhurst et al. 2006b), may similarly influence the fate of discards. Differences among these variables can be sufficient to cause immediate deaths during the gear deployments (i.e. prior to discarding) or manifest as protracted mortalities, which for many fish typically occur over up to at least $5 \mathrm{~d}$.

Variation among the factors contributing towards mortalities and their temporal influence means that in any study which seeks to quantify the fate of discarded bycatch it is necessary to collect as much information as possible during commercial fishing and then monitor the health and mortality of discards, with adequate controls, over extended periods. Our first aim was to use this approach to estimate the mortality and key contributing factors for Acanthopagrus australis and other species discarded by estuarine beach seiners and gillnetters. Based on this information, our second aim was to identify the potential for changes to operational and/or post-capture handling methods that maximise survival.

\section{MATERIALS AND METHODS}

Monitoring site and equipment used. The aims were addressed in 2 experiments done in the Clarence River system (292 $27^{\prime} \mathrm{S}, 153^{\circ} 09^{\prime}$ E; Fig. 1) between June 2006 and February 2007. For each experiment, four 10001 polyethylene (PE) holding tanks were located on the banks of a tributary (termed the 'monitoring site') that connects the Clarence River and Lake Wooloweyah (Fig. 1). All tanks were supplied with local, flowthrough sea water (at a rate of up to $631 \mathrm{~min}^{-1}$ ) and air. 


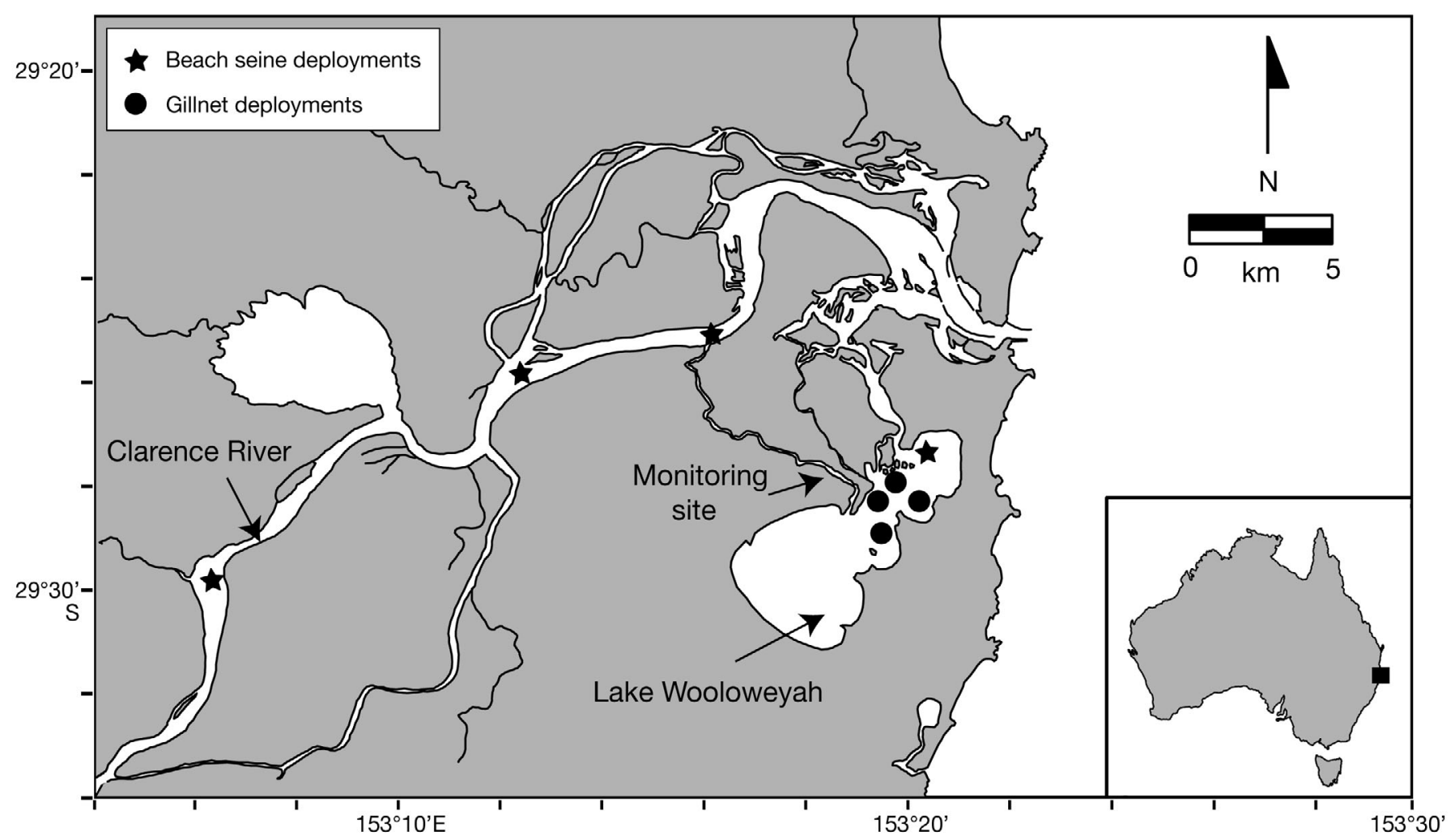

Fig. 1. Clarence River system showing the locations of the monitoring site and beach seine ( $\star$ ) and gillnet (๑) deployments

Sixty $2.5 \mathrm{~m}$ steel stanchions were secured in 2 parallel lines approximately $3 \mathrm{~m}$ apart (in $<2 \mathrm{~m}$ of water) to the bottom of the tributary near the holding tanks. Each row of stanchions had $90 \mathrm{~m}$ of $10 \mathrm{~mm}$ diameter $(\varnothing)$ rope attached horizontally at a level corresponding with the average low tide. This assembly was used to secure up to 12 small- (0.3 $\mathrm{m} \varnothing \times 0.4 \mathrm{~m}$ depth) or 110 medium( $0.5 \mathrm{~m} \varnothing \times 0.7 \mathrm{~m}$ depth) sized portable cylindrical cages made from modified polyvinyl chloride (PVC) buckets. All small and medium cages had lateral 'windows' (combined area of approximately $800 \mathrm{~cm}^{2}$ ) covered by $6 \mathrm{~mm}$ PVC mesh and clips at the top for securing to the rope. Fourteen large $(1.5 \mathrm{~m} \varnothing \times 1.5 \mathrm{~m}$ depth) cages, comprising $22 \mathrm{~mm}$ knotless polyamide (PA) netting (with $1 \mathrm{~m}$ long zippers at the top) suspended from square frames of PVC tubing $(100 \mathrm{~mm} \varnothing)$ and weighted by 2 stainless-steel rings, were anchored (in depths of 2 to $2.5 \mathrm{~m}$ ) within $100 \mathrm{~m}$ of the stanchions. The small and large cages were used during the beach seine experiment, while the medium cages were used during the gillnet experiment according to differences among the species and sizes of fish encountered and the methods of retrieving the gears (see below).

A fish-transport system consisting of either eight 751 PVC containers (beach seine experiment) or the medium cages (gillnet experiment) filled with aerated water was designed to fit into a $4 \mathrm{~m}$ dory. The 751 PVC containers were of sufficient size that 2 of the small cages could fit inside. Water quality (oxygen, $\mathrm{pH}$, salinity and temperature) was monitored in all containers using an Horiba U 10 meter and maintained (through water exchange) at the same level as that recorded at the deployment site.

Beach seine experiment. The first experiment was done in the Clarence River and Lake Wooloweyah (Fig. 1) between June and July 2006 and involved 8 replicate deployments of conventional beach seines by 2 crews (each with up to 3 fishers). The beach seines were similar and constructed from knotted, multistrand (1.5 mm $\varnothing$ twine) PA netting with a stretched depth of $6 \mathrm{~m}$ throughout, attached at a hanging ratio (E) of 0.5 to a $450 \mathrm{~m}$ buoyed headline and weighted foot rope. The mesh sizes were 80,57 and $42 \mathrm{~mm}$ in the anterior and posterior wings and bunt/codend, respectively (see Broadhurst et al. 2007a for further details).

Fourteen days before the first seine was deployed, 400 juvenile Acanthopagrus australis (<250 mm TL) previously collected from the Clarence River using hook-and-line and other non-invasive methods (see Uhlmann \& Broadhurst 2007 for details) were transferred from the aquaria facilities at the National Marine Science Centre in Coffs Harbour to 3 of the 
10001 holding tanks at the monitoring site. Approximately 50 common silver belly Gerres subfasciatus ( $<150 \mathrm{~mm}$ TL) were also collected from the Clarence River using cast nets and placed into the remaining 10001 holding tank. These captive A. australis and G. subfasciatus were fed and monitored daily for mortalities before being used in the experiment as controls (see below).

On each day of fishing, the beach seines were deployed at an appropriate location (dictated by fisher knowledge) during daylight and immediately before the start of either the flood or ebb tides (typically 1 deployment $\mathrm{d}^{-1}$ ). The method involved 1 fisher holding a wing end at the beach, while the other fishers deployed the seine from a motored dory in a parabolic path around the area being fished and then returned to the beach. The 3 fishers then manually retrieved the wings of the seine so that catch was herded into the bunt and pulled towards the beach at approximately $0.25 \mathrm{~m} \mathrm{~s}^{-1}$. This entire process took between 15 and $40 \mathrm{~min}$. The bunt was left in $>1 \mathrm{~m}$ of water, while the catch was removed in subsets of up to $10 \mathrm{~kg}$, placed in a tray onboard the fishing dory and sorted into retained and discarded categories by the crew. Fishers were then asked to discard individuals of unwanted and/or undersize Acanthopagrus australis, Gerres subfasciatus (MCTL of $150 \mathrm{~mm}$ ) and sand sillago Sillago ciliata (MLTL of $270 \mathrm{~mm}$ ) into the transport system onboard the dory, which was positioned alongside the bunt at the beach. G. subfasciatus were placed in groups of 3 into replicate $(n=6)$ small cages submersed in the water-filled 751 containers. In contrast, owing to their larger sizes, A. australis and S. ciliata were placed directly into the 751 containers at a maximum of 10 fish container ${ }^{-1}$. All 'discarded' fish were transported to the monitoring site within 45 min of capture and transferred by either lifting the small cages from the dory and clipping them to the rope between the stanchions or, in the case of $A$. australis and $S$. ciliata, by lifting the 751 containers from the dory and placing them upside-down (so that fish could swim out) into replicate $(\mathrm{n}=2)$ unzipped large cages (stocking densities of between 10 and 25 seined-and-discarded fish per cage). No fish were exposed to air during their transfer.

Within $30 \mathrm{~min}$ of the last seined-and-discarded individual being transferred to the monitoring site, all fish (i.e. Acanthopagrus australis or Gerres subfasciatus) in the $1000 \mathrm{l}$ holding tanks were anaesthetised (using $35 \mathrm{mg} \mathrm{l}^{-1}$ of ethyl-p-amino benzoate as per NSW Department of Primary Industries animal ethics guidelines) before the appropriate species and numbers (same as the treatment fish) were randomly selected for use as controls. The sedated control fish were scooped (in 51 PVC buckets), placed into the $75 \mathrm{l}$ con- tainers on the dory and transferred to the monitoring site as described above for seined-and-discarded fish. Control $A$. australis had their upper caudal fins clipped before being placed into the same large cages as the treatment fish. The stocking densities of G. subfasciatus in the small cages precluded this methodology, and so controls were placed into separate cages (in groups of 3). Except for Sillago ciliata (for which there were no controls), the numbers of control and seined-and-discarded fish within, or between, replicate cages were identical for all deployments. All caged fish were offered food and monitored every $24 \mathrm{~h}$ over $5 \mathrm{~d}$. To maintain stocking densities, dead individuals were removed, measured and replaced with a live individual (lower caudal fin clipped) from the $1000 \mathrm{l}$ holding tanks.

For 2 of the 8 beach seine deployments, blood samples were taken at the end of the fifth day of monitoring (following the methods described by Broadhurst et al. 2005) from 2 randomly selected seined-and-discarded and control Acanthopagrus australis in each replicate cage. Five $A$. australis were then angled from the wild (near the monitoring site) and sampled for blood within 2 min of hooking before being released. All remaining surviving individuals from the deployments were released.

Gillnet experiment. The second experiment was done in Lake Wooloweyah (Fig. 1) during February 2007 with 9 replicate deployments of a commercial gillnet. The gillnet was made from $80 \mathrm{~mm}$ PA mesh (1.5 mm $\varnothing$ twisted twine) hung at an E of 0.5 along a $750 \mathrm{~m}$ headline and foot rope, and had a stretched depth of $1.5 \mathrm{~m}$. Fishing followed conventional operations, with the gillnet deployed either at night or during the day in a straight line from a $6 \mathrm{~m}$ dory and left to fish on the bottom of the lake $(<2 \mathrm{~m}$ depth) for between 5 and 20 min. During each deployment, fishers attempted to increase fish contact with the gear by running the dory along the length of the net and splashing the water. The fishers then travelled back to the start of the gillnet and manually hauled it onto the fishing dory over a period of between 1 and $2.5 \mathrm{~h}$. Acanthopagrus australis and lesser salmon catfish Neoarius graeffei were removed from the net and, based on their MLTL or MCTL (250 and approx. $350 \mathrm{~mm}$ TL, respectively), classified as retained or discarded. Fishers were asked to release the 'discarded' individuals directly into the medium cages in the fishtransport system on the dory. For most deployments, $1 N$. graeffei or $3 \mathrm{~A}$. australis were placed into each medium cage, although in some cases, 6 A. australis were temporarily stocked in individual cages during their transfer to the monitoring site (all within $30 \mathrm{~min}$ ). These additional fish were then released into separate medium cages (so that the density of the monitored 
gilled-and-discarded $A$. australis was always 3 fish cage $^{-1}$ ), before all cages were clipped to the lines between the stanchions. None of the treatment fish were exposed to air during their transfer.

Similar-sized control Acanthopagrus australis (previously collected and placed in the 10001 holding tanks as per the beach seine experiment) were then anesthetized, fins clipped (for identification) and placed in groups of 3 into each of the medium cages containing the gilled-and-discarded individuals (providing a total stocking density of 6 fish cage $^{-1}$ ). Control Neoarius graeffei were angled (lip hooked only) within $1 \mathrm{~km}$ of the monitoring site, individually released into separate medium cages onboard the transport dory and transferred to the line between the stanchions as above. The final numbers of control and gilled-and-discarded fish were identical for all deployments. All caged fish were fed and monitored every $24 \mathrm{~h}$. Any dead A. australis were replaced as described for the beach seine experiment. Because there was a delayed mortality of seined-and-discarded $A$. australis during the first experiment (see 'Results'), the monitoring period for the gillnet experiment was extended to $10 \mathrm{~d}$.

Blood was taken (following the methods described by Broadhurst et al. 2005) from each of 4 individually caged, gilled-and-discarded and control Neoarius graeffei at the end of the monitoring periods for 6 separate deployments, and from 8 gilled-and-discarded and control Acanthopagrus australis (i.e. 2 fish from 4 cages for each group) at the end of the monitoring periods for 3 deployments. Nine N. graeffei and 4 A. australis were also angled from the wild near the monitoring site and sampled for blood (within 2 min of capture) before being released.

Data collected and statistical analyses. The following data were recorded during each gear deployment: the location, start and finish time of fishing and, for the gillnets, the time that each Neoarius graeffei and every third Acanthopagrus australis were removed from the net and discarded into the medium cages; the duration that discards were exposed to air and handled; the presence or absence of jellyfish Catostylus sp. in the nets; the numbers and weights of retained, discarded and total catches and their status (alive vs. dead); and the numbers of fish discarded into the various cages. A water quality meter (Horiba U 10) was used to record 2 replicate readings of water temperature $\left({ }^{\circ} \mathrm{C}\right)$, dissolved oxygen $\left(\mathrm{mg} \mathrm{l}^{-1}\right)$, salinity (psu) and $\mathrm{pH}$ at the surface of river or lake during fishing and then at the monitoring site when the fish were transferred.

All data were analysed separately for each species and within each experiment. The live and dead caged treatment and control fish at the end of each experiment were measured for their TL (to the nearest $0.5 \mathrm{~cm})$. Two-tailed Fisher's exact tests were used to investigate the independence of the treatment of fish (i.e. seined- or gilled-and-discarded vs. controls) on the numbers surviving at the end of each experiment. The blood samples collected from confined and angled Acanthopagrus australis and Neoarius graeffei at the end of the monitoring periods were analysed for concentrations of plasma glucose $\left(\mathrm{mmol} \mathrm{l}^{-1}\right)$ to provide an index of acute stress (Mazeaud et al. 1977, Grutter \& Pankhurst 2000, Broadhurst et al. 2007b). Glucose concentrations were derived by means of colorimetric clinical kits (Roche Diagnostics) using an enzymatic spectrophotometric assay done according to the manufacturer's instructions. Plasma glucose concentrations from angled fish (sampled within 2 min of capture) were considered baseline estimates. Hierarchical (and nested) analyses of variance (ANOVA) were used to first test for any intra-specific differences in plasma glucose among monitored treatment and control $A$. australis and Neoarius graeffei from different deployments and in different cages (A. australis only). Where there were no significant main or interactive effects of the treatment of fish, glucose concentrations from experimental fish were compared with individuals angled from the wild (baseline estimates).

Appropriate environmental, technical and biological parameters collected for the gear deployments were collated as either fixed categorical or continuous variables and, where there was sufficient replication, considered with the random factors of 'deployments' and 'cages' in mixed-effects logistic models fitted to the dichotomous status (alive vs. dead) of discarded, caged individuals at the end of the monitoring periods. These models were fitted using the lmer function within the freely available R statistical language. A stepwise variable search algorithm was employed with the most parsimonious fit based on the lowest Akaike's Information Criterion. For consistency across all model fits, random effects terms were included in the preferred model whenever they were estimated to be present (i.e. non-zero), even if not statistically significant.

\section{RESULTS}

The total, retained and discarded catches per deployment and species compositions of the beach seines and gillnets were within the ranges typically experienced for these fisheries (Tables 1 \& 2). Further, the environmental parameters recorded at the deployment and monitoring sites in both experiments were within the natural tolerance limits of all species examined, and were mostly consistent within and between replicates (Table 1). However, there were differences in salinity between the deployment (mean \pm SE of $11.9 \pm$ $3.0 \mathrm{psu})$ and monitoring $(27.9 \pm 0.3 \mathrm{psu})$ sites for Acan- 
Table 1. Mean $( \pm \mathrm{SE})$ key environmental, technical and biological variables recorded during the deployments of the beach seines $(n=8)$ and gillnets $(n=9)$ in bycatch ('discards') mortality experiments. NA: not applicable; DO: dissolved oxygen; TL: total length

\begin{tabular}{|lcc|}
\hline Variable & Beach seine & Gillnet \\
\hline Environmental & & \\
Deployment site: & & \\
Water temperature $\left({ }^{\circ} \mathrm{C}\right)$ & $16.1 \pm 0.2$ & $26.7 \pm 0.4$ \\
DO $\left(\mathrm{mg}^{-1}\right.$ ) & $9.0 \pm 0.2$ & $5.6 \pm 0.2$ \\
Salinity (psu) & $11.9 \pm 3.0$ & $28.2 \pm 0.4$ \\
pH & $8.1 \pm 0.1$ & $8.0 \pm 0.0$ \\
Monitoring site: & & \\
Water temperature $\left({ }^{\circ} \mathrm{C}\right)$ & $15.4 \pm 0.4$ & $26.2 \pm 0.3$ \\
DO (mg $\mathrm{l}^{-1}$ ) & $9.2 \pm 0.1$ & $5.4 \pm 0.2$ \\
Salinity (psu) & $27.9 \pm 0.3$ & $27.2 \pm 0.5$ \\
pH & $8.4 \pm 0.1$ & $7.9 \pm 0.1$ \\
Catch air exposure (min) & $<1$ & $<1$ \\
Technical & & \\
Deployment duration (min) & $27.0 \pm 3.5$ & $99.9 \pm 10.8$ \\
Soak time of fish (min) & $\mathrm{NA}$ & $62.6 \pm 9.4$ \\
Biological & & \\
Total catch (kg) & $52.4 \pm 14.8$ & $59.8 \pm 9.4$ \\
Retained catch (kg) & $24.1 \pm 8.7$ & $42.9 \pm 9.4$ \\
Discarded catch (kg) & $28.2 \pm 6.0$ & $16.8 \pm 4.0$ \\
Jellyfish Catolstylus sp. & Absent & Present in 1 \\
TL (mm) of monitored discards: & & deployment \\
Acanthopagrus australis & $198.5 \pm 1.3$ & $216.1 \pm 1.3$ \\
& $(\mathrm{n}=290)$ & $(\mathrm{n}=161)$ \\
Gerres subfasciatus & $129.7 \pm 3.4$ & $\mathrm{NA}$ \\
Sillago ciliata & $(\mathrm{n}=18)$ & \\
& $209.2 \pm 5.7$ & $\mathrm{NA}$ \\
Neoarius graeffei & $(\mathrm{n}=30)$ & \\
& $\mathrm{NA}$ & $337.8 \pm 4.1$ \\
& & $(\mathrm{n}=67)$ \\
\hline
\end{tabular}

thopagrus australis during the beach seine experiment (Table 1). These differences were unavoidable and reflected the need for a centralised monitoring site and the spatial and temporal deployment of the seine according to tidal movements (Fig. 1). The contribution of such variation in salinity on the mortality of seinedand-discarded $A$. australis was assessed by including this parameter in the logistic models (see next subsection).

\section{Beach seine experiment}

Bycatches from the 8 beach seine deployments comprised 11 species of fish (1837 individuals), all of which were alive at the end of sorting and prior to discarding (Table 2). A total of 290 Acanthopagrus australis (150 to $245 \mathrm{~mm}$ TL), 18 Gerres subfasciatus (110 to $155 \mathrm{~mm}$ TL) and 30 Sillago ciliata (150 to $255 \mathrm{~mm}$ TL) were released along with similar-sized controls (except for S. ciliata) into the small and medium cages (Table 3). A. australis were caught during 7 deployments, while all G. subfasciatus and S. ciliata were restricted to a single deployment (Table 3).

Overall, there were significantly greater cumulative mortalities to seined-and-discarded Acanthopagrus australis (20.3\%) and Gerres subfasciatus (72.2\%) than their controls $(0.0$ and $5.5 \%$, respectively, Fisher's exact tests, $\mathrm{p}<0.01)$. None of the seined-and-discarded $A$. australis died until the third day, after which their mortalities steadily increased until the experiment was terminated on the fifth day (Fig. 2a). G. subfasciatus demonstrated a similar, albeit less severe, rate of protracted mortality (Fig. 2a). Most seined-and-discarded Sillago ciliata (total mortality of $30.0 \%$ ) died during the first $48 \mathrm{~h}$ (Fig. 2a).

A 3-factor (comprising gear 'deployments', 'treatment of fish' and 'cages') ANOVA failed to detect significant interactions between (1) the treatment of fish and cages (nested in deployments) $\left(F_{2,8}=0.75, \mathrm{p}>0.05\right)$ or (2) the treatment of fish and deployments $\left(F_{1,2}=0.09, \mathrm{p}>0.05\right)$ on the raw concentrations of glucose in Acanthopagrus australis at the end of $5 \mathrm{~d}$ monitoring, and so these terms were pooled. No subsequent significant $F$ ratios were detected for the main effects of deployments $\left(F_{1,2}=0.01, \mathrm{p}>\right.$ $0.05)$, treatment of fish $\left(F_{1,11}=4.53, \mathrm{p}>\right.$ $0.05)$ or cages $\left(F_{2,11}=3.83, \mathrm{p}>0.05\right)$, although the latter 2 factors had $\mathrm{p}$ values of 0.055 and 0.057 , respec- 
Table 3. Numbers of live and dead seined- and gilled-and-discarded Acanthopagrus australis, Gerres subfasciatus, Sillago ciliata and Neoarius graeffei for each relevant replicate deployment at the end of each experiment. -: not applicable

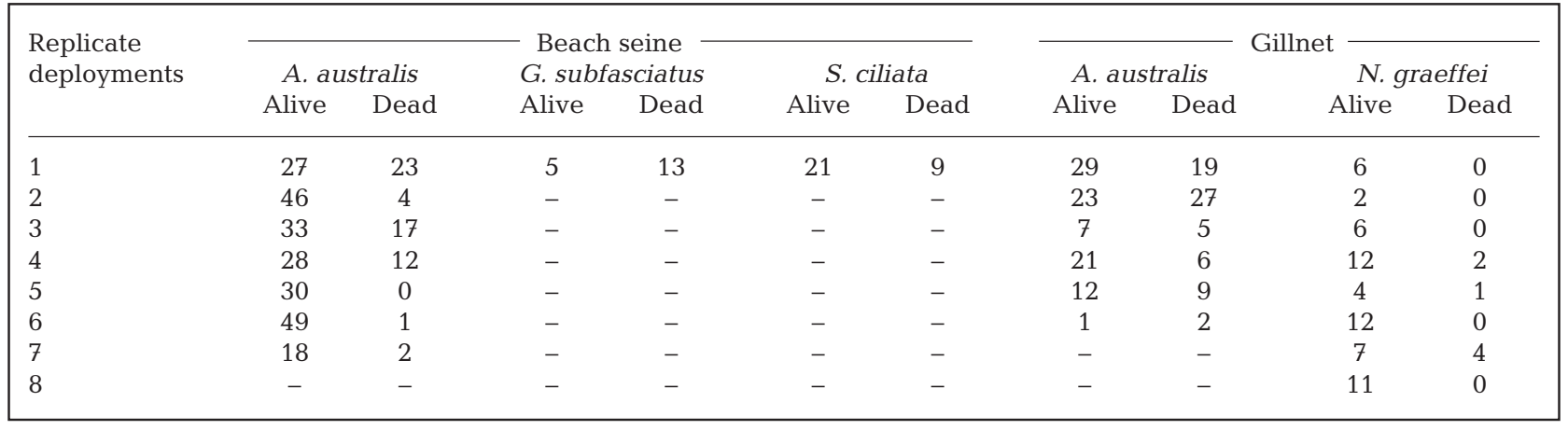

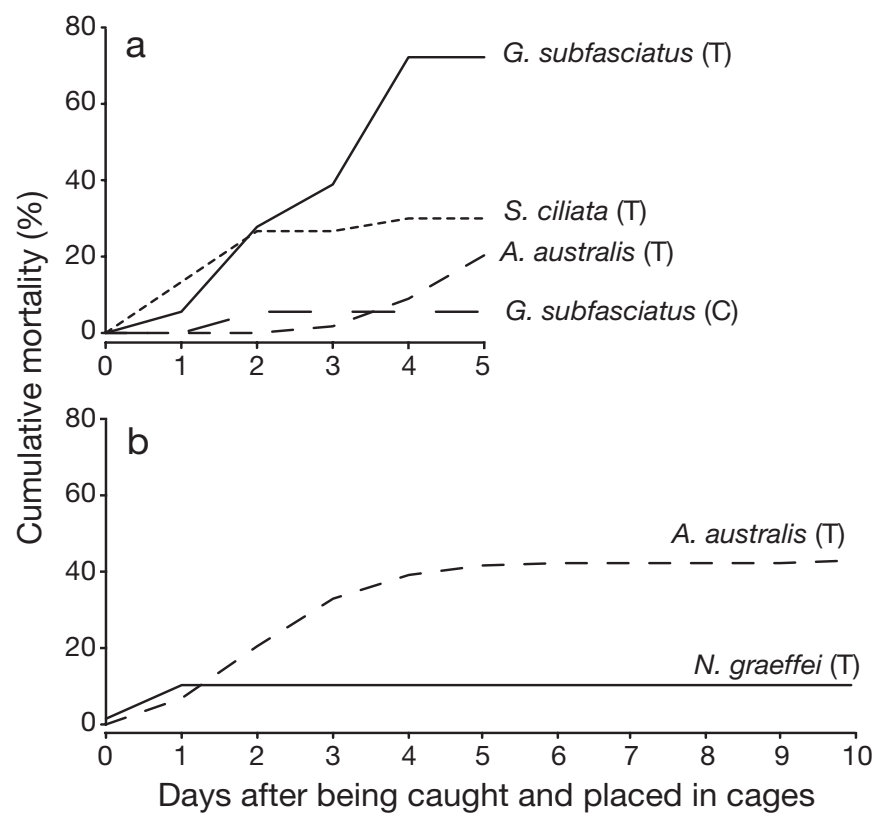

Fig. 2. Cumulative temporal mortalities of discarded (a) Acanthopagrus australis, Sillago ciliata and Gerres subfasciatus in the beach seine experiment and (b) A. australis and Neoarius graeffei in the gillnet experiment. T: treatment; C: control

tively. There were no significant differences in mean $( \pm \mathrm{SE})$ glucose concentrations in the seined-anddiscarded $\left(4.0 \pm 0.6 \mathrm{mmol} \mathrm{l}^{-1}, \mathrm{n}=8\right)$ and control $(2.9 \pm$ $0.3 \mathrm{mmol} \mathrm{l}^{-1}, \mathrm{n}=8$ ) A. australis (pooled across deployments and cages) and baseline estimates of angled individuals (2.5 $\left.\pm 0.2 \mathrm{mmol}^{-1}, \mathrm{n}=5\right)$ (1-factor ANOVA, $\left.F_{2,18}=2.76, \mathrm{p}>0.05\right)$.

Successful mixed-effects logistic models were fitted for Acanthopagrus australis, Gerres subfasciatus and Sillago ciliata. The explanatory variables considered for inclusion in the A. australis model were (1) the short-term temporal deployment of gears - separated into midday (between 12:00 and 14: $30 \mathrm{~h}$ ) vs. morning (between 06:00 and 10:30 h) or afternoon (between
16:00 and 16:30 h); (2) deployment duration (min); (3) total catch weight $(\mathrm{kg})$; (4) TL $(\mathrm{mm})$ of monitored discards; (5) salinity (psu) and (6) temperature $\left({ }^{\circ} \mathrm{C}\right)$ at the deployment sites; and (7) differences in salinity between the deployment and monitoring sites. Different cages and deployments were included as potential random effects. Model terms were limited to main effects only, with no interactions. The most parsimonious model was reduced to the random effects of deployment and cages (both significant at $\mathrm{p}<0.05$ ) and the fixed effect of TL $(p<0.01)$. This latter variable translated to a mean $( \pm \mathrm{SE})$ reduction in the log-odds mortality of $0.045( \pm 0.010)$ per $\mathrm{mm}$ increase in TL, with the smallest observed seined-and-discarded individuals (150 mm TL) having a $47 \%$ expected probability of dying, compared with less than $10 \%$ for individuals $>216 \mathrm{~mm}$ TL (Fig. 3a).

A lack of replication for Gerres subfasciatus meant that their analysis did not include a deployment random effect or covariates measured at the deployment level, leaving only the effects of cages and TL. The cage effect was estimated to be zero and the TL effect was estimated as a reduction in log-odds of 0.016 $( \pm 0.038)$ per mm increase in length, but this was not statistically significant ( $p>0.05)$. Similarly, Sillago ciliata were caught in only one deployment, also precluding the use of deployment covariates. As for G. subfasciatus, the best model estimated no random cage effect. TL was not significant ( $p>0.05$ ), but was included for consistency and corresponded to a reduction in log-odds mortality of $0.017( \pm 0.014)$ per mm increase in length.

\section{Gillnet experiment}

Eight species (478 fish) were discarded during the 9 gillnet deployments (Table 2). As in the beach seine experiment, all fish were alive prior to discarding. A total of 162 Acanthopagrus australis and 68 Neoarius 


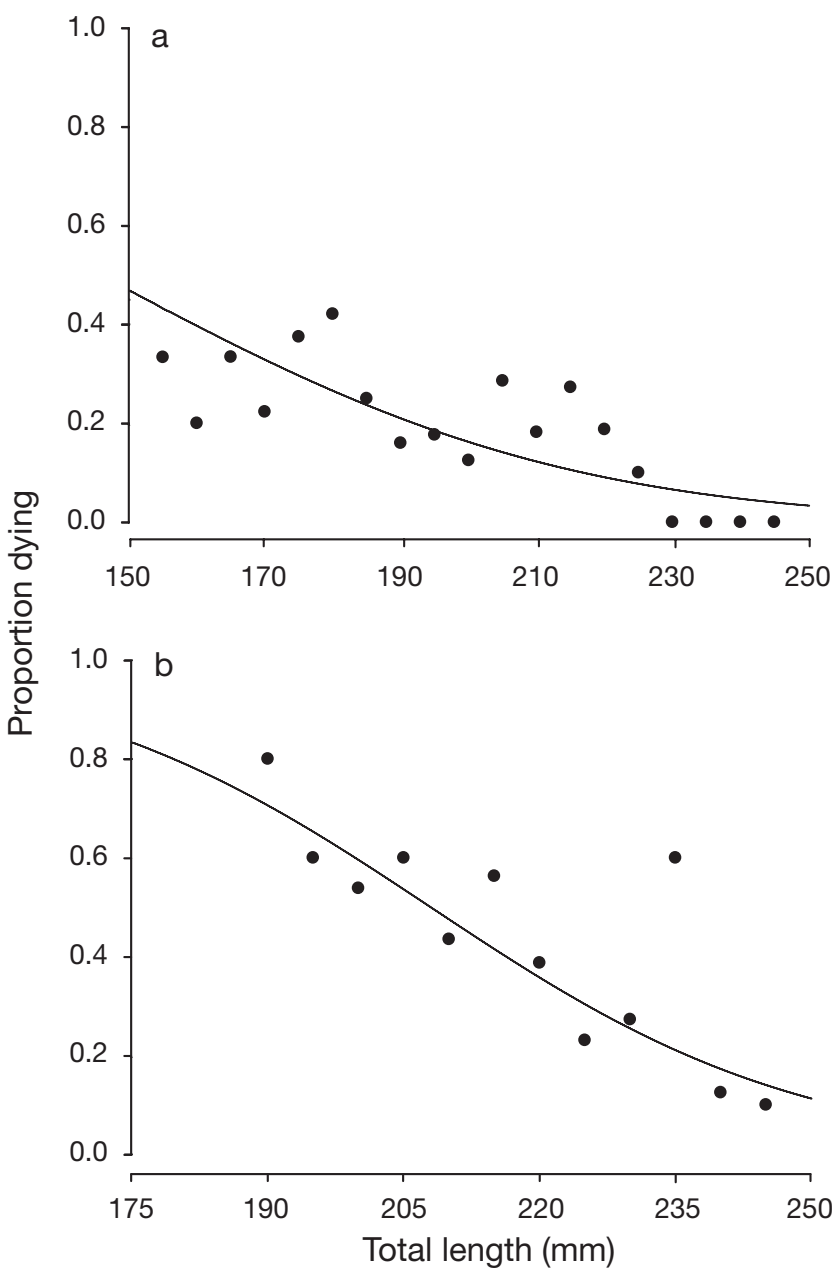

Fig. 3. Acanthopagrus australis. Logistic regression between total length (TL) and the expected proportion dying after being caught, discarded into cages and monitored for (a) $5 \mathrm{~d}$ in the beach seine experiment, or (b) $10 \mathrm{~d}$ in the gillnet experiment. Plots only include those TLs where $n \geq 4$

graeffei (80 and $25 \%$ of the total numbers discarded) caught during 6 and 8 deployments, respectively, were placed into the medium cages and monitored along with the same numbers of controls over $10 \mathrm{~d}$ (Table 3). The gilled-and-discarded fish were similar in size to their controls; A. australis ranged from 175 to $245 \mathrm{~mm}$ TL and N. graeffei from 280 to $420 \mathrm{~mm}$ TL.

None of the control fish died. One each of the gilled-and-discarded Acanthopagrus australis and Neoarius graeffei escaped during the monitoring period, while 68 and 7 of the remaining individuals of these species died, providing significant mortalities of 42.2 and $10.5 \%$, respectively (Fisher's exact test, p < 0.01 , Table 3). A. australis had a steady increase in their mortality over the first $5 \mathrm{~d}$, after which their mortalities stabilized (Fig. 2b). All 7 N. graeffei died with- in $24 \mathrm{~h}$, including 1 individual within $3 \mathrm{~h}$ of being caged (Fig. 2b).

A 3-factor ('deployments', 'treatment of fish' and 'cages') ANOVA returned a non-significant interaction between the treatment of fish and deployments $\left(F_{2,18}=\right.$ $0.18, \mathrm{p}>0.05$ ) and a non-significant main effect of the nested factor, cages $\left(F_{18,24}=0.70, \mathrm{p}>0.05\right)$ for the concentrations of glucose in Acanthopagrus australis at the end of the monitoring period. These terms were pooled, with the revised model showing a significant main effect of deployments $\left(F_{2,44}=5.63, \mathrm{p}<0.01\right)$, but not the treatment of fish $\left(F_{1,44}=0.00, \mathrm{p}>0.05\right)$. A subsequent 1-factor ANOVA revealed no significant differences in the concentrations of glucose among 4 randomly selected, gilled-and-discarded (mean $\pm \mathrm{SE}$ of $\left.2.9 \pm 0.2 \mathrm{mmol} \mathrm{l}^{-1}\right)$ and control $\left(2.5 \pm 0.2 \mathrm{mmol} \mathrm{l}^{-1}\right)$ individuals from the same deployment and baseline estimates $\left(2.9 \pm 0.1 \mathrm{mmol} \mathrm{l}^{-1}\right)$ from angled fish $\left(F_{2,9}=\right.$ 2.87, $\mathrm{p}>0.05)$.

There was no significant interaction between deployments and the treatment of fish $\left(F_{5,36}=1.13 ; \mathrm{p}>\right.$ $0.05)$ on the concentrations of glucose in Neoarius graeffei or a significant main effect of the latter (after pooling $F_{1,41}=0.42, \mathrm{p}>0.05$ ). Irrespective of the treatment of fish, differences in concentrations of glucose were detected among deployments $\left(F_{5,41}=2.56, \mathrm{p}<0.05\right)$. There were no significant differences in the concentrations of glucose among 8 randomly selected gilledand-discarded $\left(2.2 \pm 0.1 \mathrm{mmol} \mathrm{l}^{-1}\right)$, control $(2.1 \pm$ $\left.0.2 \mathrm{mmol} \mathrm{l}^{-1}\right)$ and angled $\left(2.0 \pm 0.1 \mathrm{mmol} \mathrm{l}^{-1}\right)$ N. graeffei (1-factor ANOVA, $F_{2,21}=0.81, \mathrm{p}>0.05$ ).

Mixed-effects logistic models were converged for Acanthopagrus australis and Neoarius graeffei. The explanatory variables considered for inclusion were (1) night (between 20:30 and 05:15 h) vs. day (between 08:00 and $15: 30 \mathrm{~h}$ ); (2) soak time of fish (min); (3) TL $(\mathrm{mm})$ of discarded monitored fish; and (4), salinity (psu) and (5) temperature $\left({ }^{\circ} \mathrm{C}\right)$ at the deployment sites. Different deployments and cages (A. australis only) were included as potential random effects. The presence or absence of jellyfish was also included for $N$. graeffei. For $A$. australis, the best model estimated a non-significant effect of deployments $(p>0.05)$ and no effect of cages. The only significant fixed effect was TL $(p<$ 0.01 ), which corresponded to a reduction in the logodds mortality of $0.050( \pm 0.013)$ per $\mathrm{mm}$ increase in length, so that the smallest gilled-and-discarded individuals (175 mm TL) had an $83 \%$ expected probability of dying, compared with $11 \%$ for those at $\geq 250 \mathrm{~mm} \mathrm{TL}$ (Fig. 3b). The best model for $N$. graeffei found no random effects ( $p>0.05)$, but did detect a significant fixed effect of the presence of jellyfish $(p<0.05)$. The effect of TL was estimated to be a reduction in log-odds mortality of $0.015( \pm 0.014)$ per mm increase, but this was not statistically significant $(p>0.05)$. 


\section{DISCUSSION}

The fate of organisms discarded during commercial fishing is strongly influenced by the cumulative effects of a suite of technical (e.g. gear design and deployment methods), environmental (e.g. temperature, hypoxia and the availability of light) and biological (e.g. physiology, size, and catch volume and/or composition) factors (Davis 2002, Broadhurst et al. 2006b). Inherent fishery-specific differences mean that the importance of these individual factors varies considerably, but there are some general trends in the magnitudes of observed impacts. For example, industrial fisheries involving towed gears like trawls that actively direct large quantities of organisms into codends over extended periods often cause considerable damage to discarded fish and immediate or short-term mortalities that approach 100\% (Broadhurst et al. 2006b). By comparison, the impacts of smaller-scale and/or passive gears, including some gillnets, are typically less severe and often associated with fewer than $50 \%$ mortalities (Murphy et al. 1995, Gallinat et al. 1997, Farrell et al. 2000, 2001, Vander Haegen et al. 2004, Buckel et al. 2006, Uhlmann \& Broadhurst 2007).

Except for Gerres subfasciatus, the observations in the present study support the consensus above, with no immediate deaths to any of the 2730 individuals comprising discards from both gears, and short-term mortalities between 10 and $43 \%$ for Acanthopagrus australis, Sillago ciliata and Neoarius graeffei. The generally lower proportions of dead than live discards can be attributed to the common operational characteristics of the beach seines and gillnets. Although their catching methods differed (i.e. active vs. passive), both gears were deployed for short periods (means of $<63 \mathrm{~min})$ in shallow water $(<2 \mathrm{~m})$, with organisms quickly sorted and exposed to air for less than $1 \mathrm{~min}$ prior to being discarded. Further, catches in the beach seine were not large (mean of $41 \mathrm{~kg}$ ) relative to the volume of the codend/bunt (i.e. 4 to $7 \mathrm{~m}$ in circumference $\times 9 \mathrm{~m}$ in length; Broadhurst et al. 2007a) and were unlikely to be compressed or overly crowded. Such factors can be considered fairly mild in terms of their known ranges of impacts on discards (Broadhurst et al. 2006b).

Notwithstanding the general pattern above, there were differences among species tolerances to the catch-and-discarding mechanisms of each gear, clearly illustrated by the relatively greater mortality $(70 \%)$ of seined-and-discarded Gerres subfasciatus than the other species. Uhlmann \& Broadhurst (2007) observed similar rates of death and massive associated physical trauma (scale loss and lesions) to this species (and Castelnau's herring Herklotsichthys castelnaui) after the fish had been discarded from estuarine penaeid seiners and trawlers. These earlier observations were attributed to the general fragility of G. subfasciatus and their inability to avoid or withstand collisions with meshes and other organisms during their progression along netting panels into codends, and the subsequent build-up of catch. Comparable impacts would have occurred in the beach seines as fish were herded by the wings and into the bunt. All G. subfasciatus were considerably smaller than the other species and, because TL is positively correlated to swimming speed and endurance (Beamish 1978), they would have tired more rapidly. Fatigued fish are less able to respond to stimuli in the gear, which can exacerbate physical impacts (Broadhurst et al. 2006b).

The importance of TL in contributing towards mortality is supported by the parsimonious logistic model for Acanthopagrus australis, with seined-and-discarded fish at $150 \mathrm{~mm}$ TL having a $47 \%$ probability of dying versus $<10 \%$ for fish $>216 \mathrm{~mm}$ TL. Compared with their larger conspecifics, smaller $A$. australis may have been less able to avoid tactile stressors during their capture in the beach seines. However, unlike Gerres subfasciatus, A. australis have hard scales, are physically robust and apparently quite resilient to a range of impacts with different fishing gears (Broadhurst et al. 2005, 2007b, Uhlmann \& Broadhurst 2007). While there were no concomitant, significant effects of TL on the mortality of Sillago ciliata, this may reflect their smaller sample size (i.e. 30 individuals caught in 1 deployment). Further research is required to more clearly elucidate the cause(s) of their mortalities.

TL was also a significant predictor of mortality for gilled-and-discarded Acanthopagrus australis, which again may be explained by a positive correlation between size and general resilience. However, it is equally likely that the methods by which fish were removed from the gear had some interaction. During retrieval, most $A$. australis were impinged in multiple meshes, usually along their body (small fish), or around their head (larger fish). Depending on their girth, smaller fish were removed by pulling them forwards through the meshes, while larger individuals were pushed backwards. Forcing individuals between 195 and $225 \mathrm{~mm}$ TL (e.g. those with a maximum girth close to the maximum stretched mesh perimeter; Broadhurst et al. 2006a) through meshes may have either (1) damaged their internal organs and/or (2) caused skin injury that ultimately contributed towards their mortality. In support of the latter impacts, like other studies (e.g. Vander Haegen et al. 2004), we observed that dead fish had massive scale loss at, and posterior to, their point of meshing.

The mortalities for gilled-and-discarded Neoarius graeffei $(10.5 \%)$ were not significantly associated with $\mathrm{TL}$, and while this result might be a function of their 
much greater relative sizes (i.e. 280 to $420 \mathrm{~mm}$ TL), their morphology and method of capture may also have precluded any correlation. Irrespective of TL, most $N$. graeffei were entangled on their rigid dorsal and pectoral spines, rather than being meshed along their body. Because their spines contain poison and can inflict serious wounds to fishers, $N$. graeffei were carefully removed from the net (although some spines were broken by fishers). The few subsequent deaths were apparently caused by a sporadic presence of jellyfish in 1 deployment, with afflicted individuals having clear contact marks along their flanks. Conceivably, Acanthopagrus australis and the other species could incur similar injuries and associated mortalities; however, insufficient numbers were exposed to jellyfish to test for any effects.

There were no other predictors of mortality for fish discarded from either of the gears. Nevertheless, factors which were examined, but did not have sufficient magnitudes of differences and/or replication to be detected, could still affect the fate of discards. One important factor might be water temperature (Davis 2002, Broadhurst et al. 2006b). For example, Murphy et al. (19956) and Bettoli \& Scholten (2006) observed positive correlations between water temperature and the mortality of spotted sea trout Cynoscion nebulosus and paddle fish Polyodon spathula caught in inshore marine and freshwater gillnets, respectively. These results were attributed to exacerbated physiological responses at the higher temperatures. A lack of temporal replication in the present study precludes any accurate assessment of temperature-related mortality, although for Acanthopagrus australis, the much warmer water recorded during the gillnet deployments (mean \pm SE of $26.7 \pm$ $0.4^{\circ} \mathrm{C}$, Table 1) may have contributed towards the greater mortalities than those observed from the seine $\left(16.1 \pm 0.2^{\circ} \mathrm{C}\right.$, Table 1$)$.

In addition to undetected causal effects, there are likely to be other relevant components of unaccounted fishing mortality that were not quantified here, particularly those caused by predation (Ryer 2002, 2004). Given that there were no significant differences between the plasma glucose concentrations of angled (baseline) and caged Acanthopagrus australis at the end of the 2 experiments, it is likely that most surviving fish had recovered from any physiological impacts evoked during their capture and discarding (especially after $10 \mathrm{~d}$ ). However, all species except Neoarius graeffei incurred mortalities for up to $5 \mathrm{~d}$, suggesting at least some protracted negative response to their treatment. In the wild, any impaired fish may be more vulnerable to a range of predators, which could add considerably to their overall mortality models (Broadhurst et al. 2006b).
The method of confining discards in cages in this study precludes any attempt at fully partitioning their mortality into the various unassessed components, such as predation (Broadhurst et al. 2006b). Future research would benefit from a more holistic assessment of the fate of species discarded by beach seiners and gillnetters and any short-or medium-term negative impacts associated with stress and/or changes in behaviour and physical condition. The potential for at least some remaining cryptic mortality due to such impacts means that the observations here can at best be considered minimum estimates.

Irrespective of other unaccounted mortalities, the results from this study provide some direction towards developing modifications that maximise the survival of discards. Clearly, it would seem advisable to regulate the selectivity of both gears as closely as possible to the legal sizes of the targeted species, since limiting the catches of smaller Acanthopagrus australis would considerably reduce their mortality. Carefully removing those remaining unwanted gilled $A$. australis might further protect this species. Avoiding setting gillnets during high abundances of jellyfish would have a similar impact on Neoarius graeffei. Another option proposed during previous studies is to use onboard 'recovery' or 'revival' boxes, fitted with flow through water and designed to allow some fish to recuperate from catch-induced stressors prior to being discarded (Farrell et al. 2000, 2001). Combined with technical modifications (see 'Introduction') to improve selection during fishing, such simple practices could considerably reduce the unaccounted fishing mortality of estuarine beach seiners and gillnetters.

Acknowledgements. This work was funded by the NSW department of Primary Industries and the Australian Fisheries Research and Development Corporation (Grant no. 2005/056) and approved by the NSW DPI Animal Care and Ethics Committee (ACEC REF 05/10). We thank the Clarence River commercial fishers for their contribution and ongoing support, and A. Hulme and S. McGrath for technical assistance.

\section{LITERATURE CITED}

Basaran F, Samsun N (2004) Survival rates of black sea turbot (Psetta maxima maeotica, L. 1758) broodstock captured by gill nets from different depths and their adaptation culture conditions. Aquac Int 12:321-331

Beamish FWH (1978) Swimming capacity. In: Hoar WS, Randall DJ (eds) Fish physiology, Vol VII. Locomotion. Academic Press, New York, p 101-187

Bettoli PW, Scholten GD (2006) Bycatch rates and initial mortality of paddle fish in a commercial gillnet fishery. Fish Res 77:343-347

Broadhurst MK, Gray CA, Young DJ, Johnson DD (2003) Relative efficiency and size selectivity of bottom-set gill-nets for dusky flathead, Platycephalus fuscus and other species in New South Wales, Australia. Arch Fish Mar Res 50:287-300 
Broadhurst MK, Gray CA, Reid DD, Wooden MEL, Young DJ, Haddy JA, Damiano C (2005) Mortality of key fish species released by recreational anglers in an Australian estuary. J Exp Mar Biol Ecol 321:171-179

Broadhurst MK, Dijkstra KKP, Reid DD, Gray CA (2006a) Utility of morphological data for key fish species in southeastern Australian beach-seine and otter-trawl fisheries: predicting mesh size and configuration. NZ J Mar Freshw Res 40:259-272

Broadhurst MK, Suuronen P, Hulme A (2006b) Estimating collateral mortality from towed fishing gear. Fish Fish 7 : 180-218

Broadhurst MK, Wooden MEL, Millar RB (2007a) Isolating selection mechanisms in beach seines. Fish Res 88:56-69

Broadhurst MK, Butcher PA, Brand CP, Porter M (2007b) Ingestion and ejection of hooks: effects on long-term health and mortality of angler-caught yellowfin bream Acanthopagrus australis. Dis Aquat Org 74:27-36

Buckel JA, Hines RJ, McArthur TC (2006) Incidental catch and discard of red drum, Sciaenops ocellatus, in a large mesh Paralichthyidae gillnet fishery: experimental evaluation of a fisher's experience at limiting bycatch. Fish Manag Ecol 13:113-119

Davis MW (2002) Key principles for understanding fish bycatch discard mortality. Can J Fish Aquat Sci 59: 1834-1843

Farrell AP, Gallaugher P, Clarke C, DeLury N, Kreiberg H, Parkhouse W, Routledge R (2000) Physiological status of coho salmon (Oncorhynchus kisutch) captured in commercial nonretention fisheries. Can J Fish Aquat Sci 57: 1668-1678

Farrell AP, Gallaugher PE, Fraser J, Pike D and others (2001) Successful recovery of the physiological status of coho salmon on board a commercial gillnet vessel by means of a newly designed revival box. Can J Fish Aquat Sci 58:1932-1946

Fritz KR, Johnson DL (1987) Survival of freshwater drums released from Lake Erie commercial shore seines. N Am J Fish Manag 7:293-298

Gallinat MP, Ngu HH, Shively JD (1997) Short-term survival of lake trout released from commercial gill nets in Lake Superior. N Am J Fish Manag 17:136-140

Gray CA (2002) Management implications of discarding in an estuarine multi-species gill net fishery. Fish Res 56: $177-192$

Gray CA, Kennelly SJ (2003) Catch characteristics of the commercial beach-seine fisheries in two Australian barrier estuaries. Fish Res 63:405-422

Gray CA, Larsen RB, Kennelly SJ (2000) Use of transparent netting to improve selectivity and reduce bycatch in fish seine nets. Fish Res 45:155-166

Editorial responsibility: Robin Overstreet,

Ocean Springs, Mississippi, USA
Gray CA, Kennelly SJ, Hodgson KE, Ashby CJT, Beatson ML (2001) Retained and discarded catches from commercial beach-seining in Botany Bay, Australia. Fish Res 50: 205-219

Gray CA, Johnson DD, Young DJ, Broadhurst MK (2004) Discards from the commercial gillnet fishery for dusky flathead, Platycephalus fuscus, in New South Wales, Australia: spatial variability and initial effects of change in minimum legal length of target species. Fish Manag Ecol 11:323-333

> Gray CA, Johnson DD, Broadhurst MK, Young DJ (2005a) Seasonal, spatial and gear-related influences on relationships between retained and discarded catches in a multispecies gillnet fishery. Fish Res 75:56-72

Gray CA, Broadhurst MK, Johnson DD, Young DJ (2005b) Influences of hanging ratio, fishing height, twine diameter and material of bottom-set gillnets on catches of dusky flathead Platycephalus fuscus and non-target species in New South Wales, Australia. Fish Sci 71:1217-1228

- Grutter AS, Pankhurst NW (2000) The effects of capture, handling, confinement and ectoparasite load on plasma levels of cortisol, glucose and lactate in the coral reef fish Hemigymnus melapterus. J Fish Biol 57:391-401

Kennelly SJ, Gray CA (2000) Reducing the mortality of discarded undersize whiting Sillago ciliata in an estuarine seine fishery. Mar Freshw Res 51:749-753

- Manire C, Hueter R, Hull E, Spieler R (2001) Serological changes associated with gill-net capture and restraint in three species of sharks. Trans Am Fish Soc 130: 1038-1048

> Mazeaud MM, Mazeaud F, Donaldson EM (1977) Primary and secondary effects of stress in fish: some new data with a general review. Trans Am Fish Soc 106:201-212

> Murphy MD, Heagey RF, Neugebauer VH, Gordon MD, Hintz JL (1995) Mortality of spotted seatrout released from gillnet or hook-and-line gear in Florida. N Am J Fish Manag 15:748-753

Ryer CH (2002) Trawl stress and escape vulnerability to predation in juvenile walleye pollock: Is there an unobserved bycatch of behaviorally impaired escapees? Mar Ecol Prog Ser 232:269-279

Ryer CH (2004) Laboratory evidence for behavioural impairment of fish escaping trawls: a review. ICES J Mar Sci 61:1157-1164

> Uhlmann SS, Broadhurst MK (2007) Damage and partitioned mortality of teleosts discarded from two Australian penaeid fishing gears. Dis Aquat Org 76:173-186

> Vander Haegen GE, Ashbrook CE, Yi KW, Dixon JF (2004) Survival of spring Chinook salmon captured and released in a selective commercial fishery using gill nets and tangle nets. Fish Res 68:123-133

Submitted: October 17, 2007; Accepted: February 5, 2008

Proofs received from author(s): May 10, 2008 